\title{
LA INFANCIA EN EL SIGLO XXI: BIOPOLÍTICA DE UN CUERPO EN CONSTRUCCIÓN SOCIAL
}

\author{
José-Luis Anta Félez \\ Universidad de Jaén - Área de Antropología Social \\ Almudema García Manso \\ Universidad Rey Juan Carlos de Madrid
}

https://doi.org/10.33676/EMUI_nomads.55.11

Resumen: Este trabajo pretende realizar una reflexión sobre el biopoder y su relación con la infancia. La infancia es considerada como un periodo del ciclo vital del sujeto humano casi idílico e intocable, pero que constituye uno de los escenarios más fértiles para el biopoder. Desde aquí realizamos un breve recorrido por las consideraciones teóricas acerca del biopoder, su acción en la infancia y una pequeña revisión de dos aspectos fundamentales en el siglo XXI: la infancia farmacotizada y tecnificada.

Palabras clave: biopoder; biopolítica; cuerpo; infancia; cyborg; sistema de consumoproducción; farmacopornografía

\section{Childhood in the XXXI Century: Biopolitic of a Body in social construction}

Abstract: This work aims to make a reflection on biopower and its relationship to children. Childhood is considered a period of almost idyllic life cycle and untouchable human subject, but it is one of the most fertile biopower scenarios. From here we make a brief review of the theoretical considerations of biopower action in childhood and a brief review of two fundamental aspects in the XXI century: a childhood narcotized and technically.

Keywords: biopower; biopolitics; body; childhood; cyborg; consumption-production system; pharmapornography

\section{Biopolítica y sujeción del sujeto viviente.}

"La sociedad, subsumida bajo un poder que desciende hasta centros vitales de la estructura social y de sus procesos de desarrollo, reacciona como un único cuerpo. El poder se expresa así como un control que invade las profundidades de las consciencias y de los cuerpos de la población -y que se extiende, al mismo tiempo, a través de la integralidad de las relaciones sociales" (Negri; Hart, 2002).

El cuerpo del mundo contemporáneo más reciente, está sujeto a los ejercicios de poder del sistema que gobierna. Este poder hoy por hoy no es otro que el de un sistema orientado a producir capital y normas de consumo bajo las leyes del mercado global y postcapitalista. Un cuerpo que ve cómo su existencia se debe a la construcción de los medios de comunicación de masas en su ser y estar en el mundo. Este cuerpo es, 
fundamentalmente, procesado digitalmente, tratado y modelado por los fármacos y la ciencia médica, compulsivamente nutrido o dejado, en un contrario absoluto, de proporcionarle alimento y anulado por la presencia permanente de ornamentos y anexos que a él se adhieren, en definitiva, el cuerpo es una mercancía fetichizada (Marinas, 2001). Un cuerpo que adquiere su valor como objeto que se vende, que está unido a una cultura del espectáculo y que es construido de forma previsible desde los mass media. Todo este enorme entramado de elementos definitorios del cuerpo no son sino el efecto de una estructura de lo que Foucault trato como el biopoder, que entraba en el juego del desarrollo teórico de la mano de su obra La voluntad del saber (1976) y su curso el Nacimiento de la biopolítica (2009), aunque muchas de las ideas al respecto ya aparecía en las instituciones disciplinarias analizadas en Vigilar y castigar (1975), obra en la que ya es abordado el biopoder como el primero de los dispositivos políticos de control social.

En este sentido, las disciplinas, que comienzan a desarrollarse en los siglos XVII y XVIII en instituciones tales como son la escuela, las prisiones, el cuartel o los hospitales, instituciones de encierro que tienen como objetivo la disciplinación de las subjetividad del cuerpo, siendo su principal función la de aumentar la utilidad del individuo mediante el "control minucioso de cada cual sobre su propio cuerpo", a través de la contemplación, análisis y examen de los gestos y las actitudes de los cuerpos-sujetos. Las disciplinas, así, pues, tratan de normalizar a los sujetos, intentando conseguir que se sometan a la vez a la obediencia y a su utilidad dentro de las cadenas de producción-consumo. Respecto a las instituciones, donde todo esto viene a tomar forma, se ha de considerar la importancia que posee la conformación de un conjunto de saberes-poderes, tales como son la pedagogía, la psiquiatría, la medicina, el arte militar, la criminalística, la sociología o la biología que fueron, poco a poco, adquiriendo cierta legitimidad e influencia sobre los sujetos y su conformación corporal.

En efecto, el propio Michel Foucault, ya localiza a finales del siglo XVIII, las principales técnicas de la biopolítica, que no son otras que los mecanismos reguladores del entramado conformado por una narrativa, subjetividad y práctica asociado a los dispositivos de seguridad, disciplinamiento y control. Estos mecanismos son identificados por Foucault, como un conjunto de estrategias políticas, destinadas a ordenar toda una serie de procesos de orden biológico, que en su conjunto forman el entramado de cómo se explica el orden del cuerpo social: los índices socio-demográficos de la natalidad, mortalidad, esperanza de vida, edad media al matrimonio, etc. Índices cuyo objetivo radica en incrementar las fuerzas del Estado, tanto en cuanto que les permite remarcar sus políticas, como reformular en función de sus intereses y que, en cierta medida, refuerzan con ello la idea de la seguridad y el control de los riesgos. Unas tecnologías, por lo tanto, centradas en la vida, que trataban de controlar los efectos de la masa 
social, los procesos bio-sociológicos, la morfología de la población. Es su cuantificación y su reducción a índices lo que hace que esta ciencia de la población se convierta en uno de los objetivos y tecnología de la biopolítica.

Desde esta perspectiva la biopolítica hace referencia directa al ejercicio de un tipo de poder co-extensivo con la vida, es decir, lo que hace que la vida humana, como concepto político, forme parte del cálculo del gobierno, entendido todo ello como conducción de prácticas. La biopolítica está compuesta de dos partes que la remarcan como una gran máquina de poder: el dispositivo disciplinario y los mecanismos de seguridad. Los biopoderes, desde aquí, vendrían a ser el conjunto de técnicas orientadas a multiplicar, controlar y alargar la vida. Desde su advenimiento a finales del siglo XVIIII y principios del XIX, hasta el día de hoy, los dispositivos biopolíticos, sus técnicas, enfoques, objetivos, instituciones y tecnologías han ido cambiando adaptándose a las diferentes racionalidades de gobierno que han ido sucediéndose desde entonces. Sobre todo centrándonos en una sociedad occidental, alfamente capitalizada, globalizada, mediatizada, tecnificada, medicalizada, consumista y sujeta a unos principios económicos y políticos propios del Estado liberal, una evolución perversa del otrora Estado del bienestar, todo ello diseñado tras la ll Guerra Mundial.

En este medio el sujeto y su cuerpo poseen unas funciones establecidas por un sistema de valor-poder, sistema que desde la biopolítica y la anatomopolítica (Foucault, 2009), caracterizada por ser una tecnología individualizante del poder, basada en el escrutar en los individuos sus comportamientos y su cuerpo, con el fin de anatomizarlos, es decir, producir cuerpos dóciles y fragmentados. Todo ello apunta al sometimiento de los cuerpos por parte del sistema de poder que gobierna, el cual cincela y moldea los cuerpos a merced de unos intereses claros: su adecuación a un sistema, a sus valores y su utilidad. Este biopoder en la actualidad se ve transformado en una suerte de capacidad de cambio permanente e incide directamente sobre el cuerpo: un biopoder digital, capitalista y carnal que actúa sobre los cuerpos, no sólo sobre la acción de los cuerpos sino sobre los cuerpos en sí. De ahí que la capacidad de plasticidad de las tecnologías del cuerpo actuales son tales que el cuerpo se convierte prácticamente en un lienzo en blanco.

Todo esto entra de lleno en lo que Beatriz Preciado ha bautizado, apadrinado por el concepto de biopoder, como farmacopornografía. La representación de los cuerpos desarrollada por Beatriz Preciado en su obra Testo Yonki (Preciado, 2008) y en Pornotopia. Arquitectura y sexualidad en 'Playboy' durante la guerra fría (Preciado, 2010) viene a mostrar unos cuerpos propios de la sociedad que rebasa el postmodernismo, una sociedad hipercapitalista, cristalizada en las sociedades occidentales actuales y en sus emergentes clones ubicados en los denominados BRIC (Brasil, Rusia, India y China), unos cuerpos - 
unidos a sus sujetos vivientes- que son mediados por técnicas socio semióticas, tales como la pornografía y los medios de comunicación de masas, y biomédicas, o lo que Preciado denomina farmacología-que vienen a ser las disciplinas médicas, quirúrgicas, farmacéuticas y sanitarias en general-. Repitiendo la historia del poder y su capacidad de moldear sujetos, los cuerpos actuales se hallan sometidos de algún $u$ otro modo al control, mediación y delimitación de las técnicas socio semióticas y biomédicas anteriormente indicadas.

La subjetividad mueve al sistema actual de producción y reproducción capitalista a través de la generación de "estados mentales y psicosomáticos de excitación, relajación y descarga, de omnipotencia y de total control" (Preciado, 2008:36). Procesos tales que no se pueden desviar de su normalidad y que enmarcan un patrón estándar basado en un estilo de vida heterosexual productivo, reproductivo y clonador de estilos de vida sexo/femenino, sexo/ masculino, racialmente pautados, étnicamente mayoritarios y enfocados a una clase media acomodada, en este sentido la normalidad se acercaría demasiado a estilos de vida mayoritarios y altamente mediatizados (Beriain, 2005). La economía ha ido inundando la vida y la política de las cosas y los sujetos. El sistema capitalista, hoy en día un sistema de hipercapitalismo (Lipovestky, 2007) y liberalismo avanzado, está basado en la erradicación del Estado de Bienestar a favor de un Estado mercantilizado (Palermo, 2008) y en la creación de una espiral de consumo-producción acelerada. Una economía que inunda todas las esferas de la vida, se filtra a través del cuerpo y de sus prácticas, la socio semiótica, que invade el mundo simbólico demarcando claramente dualidades de género/sexo insondables, y la farmacología, que puede modificar y cambiar los errores de la biología como destino o incrementar las bondades del cuerpo normalizado o cuerpo bello, construyendo sexualidades hiper-generizadas.

Cuando un cuerpo no era lo suficientemente coherente con su correspondiente género, o era considerado un cuerpo anormal, tenía que re-encarnar, la sociedad posterior a la Segunda Guerra Mundial era una sociedad en cambio, precisaba de una resignificación, se tenía que proceder a un nuevo orden en las formas de mantener los géneros en su lugar, o por defecto intentar mantener cierta normalidad al respecto. La normalidad aludida es la estandarización de los sujetos a un sistema de producción-consumo propio del capitalismo, no hay que olvidar cómo en aras de la modernidad, concretamente en el periodo en el que data la acumulación capitalista y la acumulación del trabajo. En este periodo de tiempo se fue gestando la idea del sujeto moderno, un sujeto productivo, reproductivo, heterosexual, unido a una familia, no indígena, en el caso de ser indígena converso religioso -la colonización de las américas supuso una idea de sujeto converso como normal, frente al pagano que era condenado por la inquisición-, y así hasta construir una idea de sujeto modificado biopolíticamente por el nuevo 
orden que comenzaba a erigirse: el capitalismo y la necesidad de una masa poblacional que produzca (Federici, 2010).

Al igual que durante el periodo de tiempo que va desde el final del antiguo orden y el inicio del capitalismo, tras la Segunda Guerra Mundial se procede a la resignificación del sujeto normalizado y biopolíticamente construido. Un ejemplo de estas resignificaciones y reconstrucciones lo encontramos en lo narrado por Preciado (2010) en su obra Pornotopia donde nos muestra una figura de la masculinidad, encarnada en el soltero de Playboy, que en un principio podría parecer contraria a la idea de sujeto-cuerpo masculino prototípica del capitalismo de la década de los 50 y 60 del XX, pero que se convierte en un sujeto que actúa como feedback retroalimentador de las masculinidad hegemónica, su mera existencia, su capacidad de consumo y de producción mantenía la economía del macho-padre de familia prototipo biopolítico de la normatividad. A diferencia del cuerpo de la modernidad y el cuerpo de la antigüedad al cuerpo contemporáneo se le agregan los principios fordistas y su transformación en el nuevo orden del postfordismo, haciendo del cuerpo un objeto que permite una determinada producción de capital, identificada con la construcción de la imagen difundida por los medios de comunicación de masas e Internet.

Esta imagen que viene a ser la proyección del cuerpo en los medios de producción y reproducción de realidades suple las funciones sociales y culturales en la reproducción de los roles y estereotipos de género/sexo y de la normalidad del sujeto-cuerpo. Su fuerza como imagen y como sujeto de consumo hacen del cuerpo un campo de batalla en la explosión de los géneros, para ello partimos de la idea desarrollada por Beatriz Preciado de farmacopornografía como nuevo biopoder. Este nuevo escenario de poder y control sobre los sujetos vivientes se enmarca en las tecnologías de control y sujeción contemporáneas, llámense: el consumo, la medicina -en su más amplio sentido enfatizando las técnicas quirúrgicas, la genética, la química médica, la farmacología, entre otras ramas y técnicas-, los avances tecnológicos e informáticos o los medios de comunicación de masas -incluyendo a Internet como un medio más-. Todas estas tecnologías conforman una novedosa forma de concebir al sujeto-cuerpo, la capacidad de modificación químico-orgánica de algunas de estas tecnologías permiten cincelar, aún más si cabe, a los sujetos. El poder modificar la esencia química hormonal, intervenir quirúrgicamente y construir imágenes simuladas de un cuerpo hiper-tecno-bio-normativo que mantiene el orden de las cosas dentro del sistema de poder.

La ciencia, los desarrollos científico-médicos, su comercialización, su incursión como reguladores del cuerpo-sujeto-viviente normativizado hacen que el sujeto del siglo XXI se ubique en las líneas de un biopoder que construye biotipos humanos, bienes de intercambio gestionados por las multinacionales farmacéuticas. Es la ciencia en este sentido la 
que regula el lenguaje y las narrativas de lo hegemónico, un discurso y práctica de la cultura del farmacopornopoder, una ciencia que adquiere "autoridad material" (Latour, 2001) gracias a su capacidad para inventar y producir artefactos vivos y posee la capacidad de crear y no sólo describir la realidad. Crea y transforma: crea la depresión y la transforma en Prozac, crea un canon corporal estético-comercial y lo transforma en operaciones estéticas, crea una necesidad de consumir información interactiva-afectiva y lo transforma en la interacción socialcomunicación en Internet mediante redes sociales, que no son más que nuevos productos comerciales, entre otros ejemplos. Curiosamente el nuevo biopoder actúa de tal forma que no se sabe si viene antes la depresión o el Prozac, una acción de comercialización que en algunos casos se materializa en necesidades-realidades auténticamente creadas a propósito comercial. Una producción en auto-feedback que es propia del poder farmacopornográfico y que construye subjefividades toxicopornográficas definidas más por la sustancia 0 sustancias que dominan sus metabolismos, por las prótesis cibernéticas, Internet entre otras, por los tipos de deseos farmacopornográficos que orientan sus acciones (Preciado, 2008).

En este sentido, la biopolítica como proceso de sujeción, que afecta a la totalidad de la población, donde nadie escapa a su vigilancia, ni siquiera en los más remotos rincones del planeta, y donde los cuerpos no están exentos de ser moldeados por el poder que los regenta. En principio, todas las etapas vitales del ser humano se hallan a merced de los dispositivos de poder, incluyendo la infancia, un periodo de tiempo otrora olvidado por la sociedad hoy en día tan reconocido y idílicamente considerado, pero que encubre una realidad más que cruda: la infancia es uno de los ciclos vitales más influidos por las disciplinas, instituciones y tecnologías del biopoder actual, también un espacio contante de resistencias.

\section{Biopolítica y sujeción del sujeto viviente.}

"El universo de los niños ha cambiado, las propuestas y demandas del mundo adulto hacia la infancia es diferente a cualquier otro momento de la historia" (Levin, 2006: 7).

Hoy en día referirnos a la infancia es hacer referencia a uno de los periodos del ciclo vital del sujeto más fértil en representaciones e intensa en la implicación subjetiva y social. La infancia ha sido desde siempre un punto de referencias teóricas, disciplinas y prácticas, lo cual hace más complejo su abordaje, ya sea desde la disciplina antropológica, sociológica, política, médica o económica (Dolto,1996, 2006. Gaitán, 2006). La infancia en la sociedad occidental actual es considerada casi un período idílico por el cual el sujeto pasa "sin pena ni gloria", el infante 
de hoy no es considerado un sujeto que se halle inmerso en un mar de problemas, incertidumbres, complejos y supuestos vitales a los que hacer frente, la infancia en algunas sociedades occidentales es más un periodo íntimamente ligado a una niñez inocente, asexuada, incompleta y separada por completo del universo social de los adultos. Sin embargo esta visión se aleja demasiado de lo que realmente es y se entiende por infancia, este periodo del ciclo vital de gran importancia en la conformación de la personalidad adulta - desde la visión más freudiana en la relación entre infancia y psicoanálisis- y un periodo en el que la biopolítica comienza a actuar, desplegando sus dispositivos y tecnologías hábiles para la conformación del sujeto adulto (Rodríguez, 2006).

Desde la perspectiva más tradicional de la pedagogía -uno de los más influyentes dispositivos de poder en lo que se refiere a la infancia-, el siglo XX observaba al niño como un adulto en miniatura, dedicando sus esfuerzos a hacer de esos pequeños futuros hombres y mujeres de provecho, unos esfuerzos que se materializaron en el currículum oculto e institucional desplegado en la escuela (Narodowki, 2006). La pedagogía y la escuela, dispositivos de biopoder marcaron un hito en la constitución biopolítica de la infancia de manera más partícula y personalista, al niño no se le aplicaban los mismos dispositivos que a los adultos. Éstos, los niños, debían tener un espacio autónomo y apropiado para convertirse en los/as futuros/as ciudadanos/as. Es así como la escuela:

"tuvo mucho que ver con la delimitación de la infancia tanto por la difusión de un discurso psicológico, como por la expansión de una idea de minoridad-incompletud-inmadurez que colocó a la infancia en un lugar subordinado, cuya voz y perspectivas no debían tenerse en cuenta" (Dussel y Southwell, 2005).

En efecto, siendo la escuela un espacio disciplinario con dispositivos de poder adecuados para en función de las directrices propuestas por el poder dar forma a los ciudadanos del mañana. Es indudable que la infancia es una etapa de la vida igualmente sostenida, contenida y construida en un cuerpo que no es común, sino particular. Un cuerpo que ocupa un espacio, que adquiere un significado y que necesita su propia identidad, pero que es mediatizado por disciplinas y dispositivos, tecnologías de biopoder que lo irán guiando por el camino de la normatividad. No cabe aquí un estudio en profundidad de la escuela y su relación biopolítica en la conformación de los sujetos-cuerpos en la infancia, pero sí cabe resaltar que el desarrollo de la ciencia pedagógica, la psicología infantil y las innovaciones pedagógicas, así como las reestructuraciones continuas que se vienen haciendo en el sistema educativo son muestra de la gran capacidad biopolítica de la escuela, una institución social biopolítica que cincela unos sujetos en crecimiento, social, subjetiva, política y corporalmente hablando (Baño, 2010). 
Pero igualmente la construcción de la realidad es conformada en otros espacios sociales e instituciones que no son sólo la escuela ni, acaso, las prácticas formales y disciplinares (Karsten, 2003: 457-473). En la construcción de la realidad normativa entra en juego la concepción filosófica de Agamben sobre la infancia, periodo que trasciende una edad determinada adscrita al desarrollo biológico madurativo, siendo la infancia un no-lugar del lenguaje, de ahí que la infancia sea considerada desde esta perspectiva una experiencia particular "diferencia entre lo humano y lo lingüístico, que el hombre no sea desde siempre hablante, que haya sido y sea fodavía infante, eso es la experiencia" (Agamben, 2004: 70). Esto supone una dinámica existencial compleja entre el sujeto-viviente y el lenguaje, una dinámica donde la experiencia toma cuerpo en la constitución del lenguaje, una experiencia que está regulada, guiada y tutelada por las instituciones y tecnologías de poder que hacen posible dicho lenguaje. De ahí que el sujeto humano:

"en tanto que tiene una infancia, en tanto que no es hablante desde siempre, escinde esa lengua una y se sitúa como aquel que para hablar, debe constituirse como sujeto del lenguaje, debe decir yo" (Agamben, 2004: 72).

Desde esta perspectiva la infancia sea la posibilidad de apropiarse de los signos para que haya una enunciación detrás de la cual está el sujeto, que, por conservar su infancia, puede hablar de sí como viviente. En conclusión a la idea de infancia en Agamben podríamos observar que el sujeto no desde siempre está ligado al lenguaje, sino que se apodera de él pero teniendo siempre un espacio ligado a la creación, a la autonomía, a su existencia particular, a la infancia. Es por ello por lo que la infancia siempre es representada como un periodo del ciclo vital en el que los sujetos repiten, reiteran y crean situaciones que han tomado, a modo de reflejo/espejo, de la vida adulta. Los roles de género, las relaciones de violencia y afectividad, las filias y fobias tendrán una relación estrechamente ligada a lo que es representado por su inmediatez adulta. Aún así no se hayan completamente adscritos a un orden social adulto y transmitido por un lenguaje, por un discurso. De ahí que la infancia vaya tomando importancia en los intereses del discurso hegemónico, ya que es la capacidad de libre creación de los sujetos la que pone en entredicho y cuestiona los dispositivos de control hegemónicos:

"en toda sociedad la producción del discurso está a la vez controlada, seleccionada y redistribuida por cierto número de procedimientos que tienen por función conjurar sus poderes y peligros, dominar el acontecimiento aleatorio y esquivar su pesada y temible materialidad" (Foucault, 1996:14).

Esta es una de las causas por las que la infancia es tan atractiva, su captación y posterior adaptación a los discursos y narrativas 
hegemónicas hacen que sean necesarias en la posterior puesta en escena del sujeto sujetado al orden social en una sociedad de consumo-producción acelerada (Bauman, 2010). La infancia renace en este sentido como una dimensión más de control de la biopolítica. Lenguaje y experiencia vienen a ser dos de los elementos necesarios para moldear al sujeto viviente. El lenguaje compartido introduce la cultura común, una cultura que no es neutra y que actúa como mediadora, matiza los estilos de vida hasta convertirlos en estilos de vida compartidos y normativos. Una operación que inicia siendo anatómicopolítica y que deriva en la biopolítica de la población: todos los sujetos bajo los mismos parámetros, todos los sujetos biológicamente programados de idéntica forma y predeterminados y predispuestos para los mismos fines.

El considerar la infancia como estadio de vida peligroso para el discurso hegemónico, por lo que hace que ésta, la infancia, sea captada y tratada mediante dispositivos, técnicas y discursos que la homologuen y transforme en un mero período invadido por lo que en la filosofía de la Grecia clásica se comprendía bios: denotando una vida cualitativamente diferenciada e inscrita en el interior de la polis, hacia zoé, una vida desnuda, desprovista de cualquier subjetividad. Es en esta estrategia de captura y exclusión de la infancia, todo ello mediado por el lenguaje, donde el sujeto viviente ya articulado por un lenguaje adquirido desde fuera de sus experiencias, es reducido a una vida desnuda, un cuerpo biológico que no posee particularidad alguna y que ha de agruparse y normalizarse al común. Una zoé que muestra una vida reducida a los cálculos económicos, políticos, domésticos y sociales, una vida que excluye la experiencia particular del sujeto, posiblemente adquirida en la infancia, aunque esto no significa la anulación completa de la voluntad individual y la existencia de una subjetividad creadora, reveladora y autónoma del sujeto viviente (Agamben, 2003).

Pero la nuda vida, que en un principio podría parecer estar fuera de la Polis, entra en el juego político mediante las técnicas de control y las tecnologías del yo proyectadas desde los marcos jurídicos, legales y de gobierno de las diferentes instancias e instituciones sociales de poder y control. En este sentido la Carta de los derechos del niño, junto con los marcos jurídicos de cada país establecen el colchón perfecto para hacer que la carne desnuda, la vida nuda, se convierta en una vida política y normativa (Degano, 2005). Al respecto, Agamben (2004: 21) señala que esa des-subjetivización de la infancia se procede de una exclusión/inclusión en los mecanismos de poder y control establecidos por la soberanía, subraya que esta conversión nace de "algo que sólo es incluido por medio de una exclusión". En definitiva, la infancia del sujeto viviente es un periodo acaparado por los dispositivos biopolíticos con el fin de ser despolitizada de su propia política subjetiva -esa que es creada anterior a la adquisición del lenguaje común y está basada en 
las experiencias-, el sujeto viviente es llevado de la bios al zoé, administrado desde el anonimato como cifra demográfica y cuerpo normativo. La infancia transita en dos aguas, la de la defensa y preservación y la de la hostilidad e intromisión, imposición y sometimiento. Dos esferas que parecen convivir, puesto que desde la visión más crítica de la sociedad, la biopolítica lo invade todo, hasta la misma infancia tan defendida y considerada.

\section{Los biopoderes de hoy y su relación con la infancia.}

"En el new speak del hiperliberalismo semiocapitalista la expresión Multiplica tu libertad significa «multiplica tu productividad»" (Berardi, 2010).

Tomamos como punto de partida las tesis expuestas por Beatriz Preciado (2008), que analizan las visiones teóricas del biopoder y las tecnologías del yo de anteriores teóricos (Foucault, Deleuze, Guattari, Negri, entre otros), pero que parten de una novedad inusitada en todos ellos: el cuerpo-comercializado y enteramente posible de ser modificado clínica, médica y tecnológicamente hablando. Así como del auto feedback creador y constructor de subjetividades biopolíticas, hijas de una sociedad hipercapitalista y plenamente normativizante, en el que las narrativas y los discursos hegemónicos se centran en la constitución de un sujeto sujetado normativo, basado principalmente en el sistema dual género/sexo, de ahí que la mayoría de estas narrativas reproduzcan como sujeto normativo, con un género dual determinado, sexualmente heterosexual y reproductivo. Pero no sólo reproductivo demográficamente hablando, debe ser reproductivo dentro del sistema económico de consumo-producción capitalista, un sujeto que consume y produce de manera veloz, rápida, cambiante y flexible, acorde con las tendencias marcadas, un consumo enfocado a producir cuerpos y estilos de vida normativos y hegemónicos. En este proceso de normatividad de los sujetos vivientes nos encontramos tres dispositivos de poder básicos para comprender la incidencia de la biopolítica actual en el contexto de la infancia: el poder de las tecnologías de la información y la constitución del niño cyborg, la clínica, junto su proceso de medicalización, y el mercado farmacológico aplicadas a la conducta tranquila del niño o el niño farmacotizado.

Vemos cómo en la infancia, ese espacio que tantos quebraderos de cabeza trae respecto a su dual condición, -un espacio a reservar para los niños o un espacio a mediatizar por el discurso hegemónico con fines y provechos económico-sociales-, las nuevas disciplinas biopolíticas, basadas en la potencia de la tecnología, la ciencia farmacológica y el consumo -como espacio que provoca situaciones de placer y saciedad-, se despliegan con el fin ya mencionado en el anterior 
apartado: proveer al sujeto del mañana de las pautas del discurso hegemónico, ahogando su subjetividad y anulando su capacidad creativa, derivada de la experiencia, imponiendo su condición como sujeto viviente de la imposición del lenguaje hegemónico. Primero habremos de observar brevemente cómo la infancia ha sido invadida en la actualidad de la construcción médico-farmacológica de situaciones de normatividad que pretenden construir subjetividades toxico-pornográficas, que como bien señala Preciado (2008) no sabemos si esas subjetividades se han creado antes del producto de consumo farmacológico o son un efecto de ese producto. Uno de los debates en torno al niño farmacológico viene de la mano del Trastorno por déficit de atención con hiperactividad (TDAH O ADD), síndrome conductual que es tratado farmacológicamente y que se supone que entre un 3 y $5 \%$ de los/as niños/as en el mundo lo padecen (Canelotto, 2010. Sin contar con los países no occidentales). Un síndrome polémico en cuanto al gasto y consumo farmacológico que supone la constitución de una infancia que ha de ser sosegada y dócil, lo menos problemática para los padres/tutores, cuyo objetivo no sólo es el de reconducir conductas no normales sino el de mantener a los progenitores o tutores, que se suponen que son sujetos dentro del sistema productivo-consumidor capitalista, en el centro de ese sistema, sin nada que les detenga o distraiga. Así se llega a esa extraña conclusión: El/la niño/a ha de ser un niño normal, consecuentemente, nada de inquietudes más allá de las preconcebidas y las establecidas, nada de comportamientos anómalos y faltos de sosiego (Stiglitz, 2006: 75-82).

De idéntica manera, nos damos cuenta de una serie de patologías psicológicas que alteran la normalidad del discurso hegemónico y alteran las bases de la economía en general y en particular las del capitalismo caliente, basado en la producción-consumo de los cuerpos (Preciado, 2008), afectando claramente en la constitución de los futuros sujetos. Entre ellas nos encontramos con un más que notable incremento de depresiones severas en niños, hiperactividad, bipolaridad, alteraciones alimentarias, alteraciones del sueño, entre otras enfermedades. Enfermedades todas ellas tratadas con la farmacología actual: la química que altera el cerebro y las emociones. Discursos y prácticas del poder farmacológico que domestica cuerpos y permite el flujo de un mercado consumo-prodúcción correcto. En la medicina especializada en el cuerpo infantil, la pediatría, no podemos dejar de lado uno de los aspectos más emblemáticos en lo que respecta a la domesticación y maleabilidad de los sujetos-cuerpo. Tras la adecuación del protocolo de John Money para la aplicación quirúrgica de los bebés intersexuales, las intervenciones de cambio de sexo -o eufemísticamente hablando adaptación de sexo-género- en niños intersexuales son el ejemplo claro de cómo la medicina, la tecnología y la farmacología se han tornado en saberes del sujeto 
cuerpo, disciplinas biopolíticas que actúan en la normativización del sistema dual-genérico sin dejar margen a anormalidades no duales.

Pero el sistema de consumo ha generado muchos otros estilos de vida que sí inciden en la existencia y estilos de vida del niño del siglo XXI y que han venido fundamentalmente a cristalizarse en el niño farmacotizado y el niño cyborg. En efecto, entre los cambios sociales derivados del advenimiento de la sociedad hipercapitalista y metacapitalista, basada en los principios del capitalismo liberal y del capitalismo caliente, nos hallamos con una serie de factores que van a incidir en los estilos de vida infantiles, estáticos desde la década de los años 30 entre los que nos encontramos, como elemento constitutivo básico, la incursión total de la mujer al mercado laboral y la carrera profesional femenina, un hecho supuso un cambio en el concepto tradicional doméstico de la crianza, educación y socialización de los niños, dejando de ser una esfera de dominio materno para pasar a ser una esfera, bien externalizada a instituciones educativas -escuela 0 actividades extraescolares-, bien compartidas con otros familiares padres, abuelos, hermanos- o trabajadores domésticos (Gallego Ayala, 2010).

Pero también es la consolidación de la clase media, acomodada en los principios del buen gobierno del Estado, que contrae un incremento en el nivel de consumo familiar y nivel productivo, lo cual incide en la necesidad de posesión y adquisición de capital tanto más simbólico que material. Este incremento de necesidades de consumo por hogar ha supuesto que ambos cónyuges han de trabajar fuera del hogar, incluso pasar mucho tiempo haciendo vida fuera en función del consumo-producción, consecuencia inmediata de este hecho es que la educación y socialización de los niños pasa a terceros, que de manera universal se traduce en el uso constante de instituciones educativas, personal doméstico o familiares de referencia y en la mayoría de los casos medios de comunicación, principalmente, TV e Internet.

La pauperización de la seguridad y el incremento del riesgo, la urbanización de la vida familiar y el éxodo rural contraen un cambio en la forma de jugar del niño: los niños no juegan al aire libre, ni transitan libremente con otros niños, ya sean extraños o cercanos, sus juegos cambian en función del espacio que ocupan, independientemente de sea urbano o rural, además la exposición de la infancia ante las tecnologías hace que los juegos de hoy en día no sean juegos de desarrollo motriz, en su mayoría son juguetes tecnológicos o juguetes para jugar en casa, limitando por ello sus movimientos. El control y descontrol respecto a la situación del menor, incluso el mero hecho de que los padres no tengan tiempo para sus hijos, ha generado un pánico relativo por su situación, desarrollo y seguridad. Nos encontramos con las caras de una misma moneda, por un lado un pavor desmedido por controlar todos los actos del infante, lo que conlleva en muchas ocasiones a establecer sistemas de televigilancia, control a través del 
teléfono móvil y en los casos más extremos en implantes de chips de localización, frente a una absoluta dejadez por saber a que se dedican los niños mientras están frente a un televisor, ordenador o el mismo móvil (Wajcman, 2011).

En la misma línea argumental encontramos que el hábito alimenticio cambia, la falta de tiempo por una vida enfocada a la producción por consumo y nivel de vida conduce a una vida acelerada y sin tiempo para la alimentación elaborada, el hecho de la salida de la mujer tradicional del hogar familiar comporta un empobrecimiento de la salud alimenticia. Pero no sólo la culpa de la alimentación precaria, precocinada y rápida recae en la pérdida de la figura de la ama de casa, la culpa radica en los estilos de vida basados en la comodidad y la inmediatez del hecho, unos estilos de vida que inciden en la salud real del niño, el cual junto a su sedimentaria vida, basada en juegos dentro de casa y exposición en pantalla -televisión, ordenador, tablet, móvil, etc. -, ve cómo se va convirtiendo en un niño con problemas de sobrepeso (Duek, 2006: 241-265), necesitando una biopolitización de su corporalidad no sana y por ello fuera de los patrones de la normatividad.

Desde el mito cyborg de Donna Haraway (1995), señalado como ícono de la postmodernidad, conformados de manera híbrida por máquinas y organismo, nos tenemos que fijar en la infancia como posible representación tecnificada. Tal y como hemos resaltado anteriormente, los/as niños/as de hoy en día son nativos digitales (Piscitelli, 2009), han nacido inmersos en el mundo de las TICs, ellos no extrañan una vida sin tecnologías puesto que han nacido inmersos en el ciberespacio y en la omnipresencia tecnológica. Así, pues, la infancia actual es una infancia tecnificada, sus juegos, sus formas de comunicación, la representación de las realidades y la construcción de sus imaginarios sociales, el cómo los de más los representan son referencias que emergen de Internet, muchos de los adultos tienden a hacer perfiles en las redes sociales con fotografías de sus hijos, otros siguen a modo de teleconferencia o video vigilancia los pasos de sus vástagos en la guardería, pero es el concepto de juego y divertimento lo que hace del menor un usuario nativo de las TICs. No sólo nos referimos a Internet y los videojuegos, él móvil y las tabletas digitales como instrumentos de juego y diversión, ampliaciones del sujeto, nos remitimos a estas tecnologías por su capacidad de transmisión de valores, ideas, roles, estereotipos, arquetipos y estilos de vida que forman parte del discurso hegemónico y de las narrativas de la normatividad. Un ejemplo claro de ello lo encontramos en cómo los videojuegos están genéricamente marcados. La hipersexualización de los avatares femeninos, la androginia de avatares infantiles, la hipermasculinización y violencia en los avatares masculinos y el mantenimiento de los roles y arquetipos heteronormativos de género dual en las acciones y discursos emitidos a través de la información y la interacción entre el/la niño/a y lo narrado en el videojuego nos muestra 
cómo esa cyborización, que desde la teoría feminista se percibe como un mito teórico de liberación, se convierte en un dispositivo más del biopoder normativizador, donde el pequeño sujeto viviente es expuesto a las narrativas y lenguajes que conformarán su cuadro normativo y su futuro como sujeto viviente.

Encontramos, por lo tanto, que la mayor parte de la informaciónimagen que un/a niño/a puede observar tras la pantalla de un ordenador, periférico móvil o de una televisión han sido diseñadas bajo la lógica de un poder establecido, el cual desarrolla un complejo sistema simbólico basándose en el establecimiento de sus discursos mayoritarios y normativos, es cómo la inmensa mayoría de los programas infantiles, juegos, páginas webs y/o de más información que contemplan, están construyendo en ellos una imagen social de la normalidad, lo que es correcto ser en un futuro a través de un lenguaje que ellos/as puedan identificar. Dentro de ese lenguaje no sólo se encuentra la ya citada diferenciación genérica dual, sino que se encontrará inscrita toda la parafernalia dirigista propia de la esfera de poder de turno.

Internet, la televisión y los videojuegos se han ido erigiendo en los nuevos ciber-niñeros, si bien es cierto, tal y como se ha indicado anteriormente, el entorno educativo y de socialización se ha externalizado fuera de la familia, los padres delegan esas funciones en tecnologías sin en ocasiones visualizar contenidos $\mathrm{y} / \mathrm{o}$ establecer parámetros de educación. En definitiva, podemos sostener que gran cantidad de videojuegos, emisiones de televisión, información en Internet reproducen los estereotipos tradicionales de género, y con ellos los valores, prejuicios e intereses asociados, reproduciendo y exacerbando el sexismo y la violencia hacia la mujer, así como muestra un fuerte contenido en violencia y sexo, espacios en los que el niño aún no ha sido incluido y que por lo tanto desconoce, captando valores que no están dispuestos para su madurez mental y que choquen con su perspectiva acerca de la realidad (véase Amnistía Internacional, 2004).

\section{La infantopía como conclusión, deseo y consumo.}

"Esa es la pregunta básica. Cómo salvamos a los niños" (Dorfman. 2002).

En definitiva, en la sociedad capitalista el principal juego de los niños es consumir. Si entendemos que ellos son, por su parte, otro objeto de consumo, el círculo se cierra en torno a la infancia como un objeto privilegiado de la sociedad capitalista. De la misma manera se construye una puberetopia, incluso una infantopía, como lugares especialmente privilegiados para una suerte de infancia feliz, cuando en realidad no sólo son creaciones adultas, sino que ante todo son espacios donde la única posibilidad de elección es el consumo. 
Después de todo lo dicho habría que decir que el parque temático, al estilo de Disneylandia, no es el lugar de partida, sino el de llegada, es el lugar donde se juntan dos grandes conocidos: el niño y el objeto de consumo, dos ideales del deseo adulto o, dicho desde la idea política, dos concreciones de la sociedad capitalista. La infancia es en cierta medida la concreción de una agregabilidad, de una apetencia, de alguna manera podemos afirmar que el niño podía ser el producto fetiche de esa máquina deseante. El niño, como deseo de la adultez, es un resultado que sólo en su transformación de objeto de consumo, primero, y consumidor, al poco, se convierte en un privilegio del capitalismo. De hecho, si la característica de los objetos del capitalismo es que no son estáticos, sino que generan nuevas y sofisticadas formas de consumo de manera permanente, es decir, son principios activos en y para con el mercado, su simple anhelo es un derroche de goce comercial: desde cursos pre-parto, ropa especial pre-mamá y todo tipo elementos de medicina de consumo, ecografías 3D y cremas especiales para la piel, medicamentos específicos y alimentos ad hoc, hasta sesiones de fotos y fiestas donde los amigos hacen regalos a los afortunados padres.

Sujetos a un cuerpo cambiante, implementados por un mundo hormonal nuevo, controlados a múltiples niveles sobre sus actividades, prácticas y constructor, disciplinados como consumidores y sobreeducados, implementados a una porno-farmacia social, dependientes y estigmatizados los adolescentes viven bajo unas condiciones sociales muy duras. Desde que la idea del adolescente se creó en los primeros años del siglo XX hasta hoy, casi cien años después, nunca un sector social, desde la creación del proletariado, había sido tan construido, tan reivindicado y tan fijado. Parte de una subjetividad que les propone como consumidores natos y como objeto de consumo social su doble vertiente les permite ser fijados en una posición de dependencia como de estructura de negociación con las estructuras hegemónicas, con las que conviven en un sentido de tu a tu. Anclados en la ambigüedad del espacio social al que se deben y a las estructuras familiares cerradas que le proveen marcan el punto medio entre el control y la disciplina. Pero a su vez su papel ambiguo, pero no por ello menos fundamental, les pone en un lugar de control y disciplinamiento, donde se convierten en los vigilantes de su propia vigilancia. En definitiva hablamos de los adolescentes como una de esas categorías totales que la sociedad crea tanto para establecer un juego de metáforas, cuanto más de creador de símbolos con los que representar e imponer su mirada posthumanista, corporalizada y consumista. El Niño es en esta mirada parece un caso aparte (Rodríguez, 2000), a medio camino de la mascota y del autómata, del objeto humanizado y del consumo absoluto se muestra en una corporalidad que por encima de su administración está en un punto de prohibición permanente de los de más y de él hacia los demás. Truncado como proyecto personal, sin 
posibilidad de no ser más que un deseo, en su defecto una vocación deseante, el niño está sujeto a una dinámica que le convierte en un objeto casi natural, pero negado en su dimensión original, por lo que sólo puede ser la metáfora del consumo capitalista, el disciplinamiento y la sociedad del riesgo total.

En efecto, a lo largo de este trabajo, si bien hemos hecho alusión a la imagen idílica del cyborg de Haraway, nuestro planteamiento teórico se ha fundamentado en desentrañar el proceso de cibersocialización, en el que también se adentrán niños y niñas. Hemos descrito esta socialización tecnifica del individuo, mostrando las narrativas de la normatividad. Esta idea se aleja de la más bella utopía que la humanidad ha podido concebir: la posibilidad de darse forma (y destino) a sí misma. El cyborg olvida el pasado y construye el futuro; ya que está asociado inevitablemente a la representación de lo monstruoso, la construcción antinatural y liberada de la norma, es la encarnación de la diferencia. La pregunta, sin embargo, sigue siendo la misma: zpodrá también liberarse en él el discurso de la diferencia? pareciera, como si los cuerpos se transforman pero las ideologías se mantuvieran (Martínez-Collado, 2007: 113). Quizás la incorporación de la vida cyborg nos salvaría del sometimiento del biopoder. Esto nos hace reflexionar en cómo estos dispositivos del biopoder actual pueden tener efectos adversos para los discursos hegemónicos. La plasticidad y cambio de los sujetos vivientes y sus cuerpos, mediante los poderes farmacopornográficos, pueden proyectarse como estrategias de transgresión a la normatividad. Aunque estas estrategias en la infancia no serían del todo éticas y válidas -hablamos aquí de la transgresión mediante modificación corporal-, sí se podrían valer de la capacidad creativa, propia de la subjetividad infantil descrita por Agamben, una subjetividad basada en las experiencias y alejada del lenguaje hegemónico, alejándose de las tecnologías del poder. Aún así seguimos estando en una sociedad donde las narrativas y lenguajes que constituyen lo hegemónico siguen dominando a través de los cuerpos y enfatizando la infancia como espacio social de gran importancia en el ciclo vital del sujeto viviente. En última instancia la infancia, al menos como metáfora de las ideas hegemónicas, no deja de ser una gran paradoja: siendo los ciudadanos de un futuro incierto, son ya los verdaderos consumidores del presente

\section{Bibliografía}

Agamben, Giorgo (2003). El Homo sacer. El poder soberano y la nuda vida. Valencia: Pre-textos.

Agamben, Giorgo (2004). Infancia e historia: destrucción de la experiencia y origen de la historia. Buenos Aires: Adriana Hidalgo. 
Amnistía Internacional (2004). Con la violencia hacia las mujeres no se juega. Videojuegos, discriminación y violencia contra las mujeres. Documento de trabajo de Amnistía Internacional. www.amnistiacatalunya.org/edu/pdf/videojocs/04/vid-04-12.pdf

Ballesteros, Jesús; Fernández Ruiz-Gálvez, Encarnación (2007). Biotecnología y posthumanismo. Madrid: Aranzadi

Baño, Francisco Juan (2010). La escuela de la multitud. Una lectura pedagógica de los textos de Antonio Negri. Valencia: Universidad de Valencia.

Baudrillard, Jean (2000). Pantalla total. Barcelona: Anagrama.

Bauman, Zygmunt (2010). Mundo consumo. Barcelona: Paidós.

Berardi, Franco (2010). Generación post-alfa. Patologías e imaginarios en el semiocapitalismo. Buenos Aires: Tinta Limón.

Beriain, Josetxo (2005). Modernidades en disputa. Barcelona: Antrophos

Bonder, Gloria (2002). Las nuevas tecnologías de información y las mujeres: reflexiones necesarias. Santiago de Chile: Naciones Unidas.

Cannellotto, Adrián; Luchtenberg, Erwin (Comps.) (2010). Medicalización y sociedad. Lecturas críticas sobre un fenómeno en expansión. Buenos Aires: UNSAM.

Degano, Jorge A (2005). "La Minoridad y la Causa de los Niños". XII Jornadas de Investigación. Primer Encuentro de Investigadores en Psicología del Mercosur. Buenos Aires: Facultad de Psicología, UBA.

Deleuze, Gilles (1991). Foucault. Barcelona: Paidós.

Duek, Carolina (2006). "Infancia, Fast food y consumo. o cómo ser niño en el mundo Mcdonald's)". En Carli, Sandra (Comp.). La cuestión de la infancia. Entre la escuela, la calle y el shopping. Buenos Aire: Paidós.

Dussel, Ines; Southwell, Myriam (2006). "La niñez contemporánea. Aportes para repensar a los sujetos de la escuela". Revista El Monifor de la Educación, 10: 26-27.

Dolto, Françoise (1996). La causa de los niños. Barcelona: Paidós.

Dolto, Françoise (2006). Infancias. Buenos Aires: Libros del Zorzal.

Dorfman, Ariel (2002). La infancia como subdesarrollo. Madrid: Siglo XXI.

Federici, Silvia (2010). Caliban y la bruja. Mujeres, cuerpo y acumulación originaria. Madrid: Traficante de sueños.

Foucault, Michel (1994). Vigilar y castigar. Madrid: Siglo XXI.

Foucault, Michel (1996). El orden del discurso. Madrid: Endimión.

Foucault, Michel (2006). Los anormales. México: FCE.

Foucault, Michel (2009). El nacimiento de la biopolítica. Madrid: Akal. 
Gaitán Muñoz, Lourdes (2006). "La nueva sociología de la infancia. Aportaciones de una mirada distinta". Política y Sociedad, 43, 1: 9-26.

Gallego Ayala, Joana (2010). Eva devuelve la costilla: El Nuevo Estado de Conciencia de Las Mujeres. Barcelona, Icaria.

Karsten, Lia (2003). "Children's use of Public Space: The gendered world of the Playground". Childhood, 10, 4: 457-473.

Latour, Bruno (2001). La esperanza de Pandora. Ensayos sobre la realidad de los estudios de la ciencia. Barcelona: Gedisa.

Le Breton, David (1995). Antropología del cuerpo y modernidad. Buenos Aires: Nueva Visión.

Levin, Esteyan (2006). ¿̇Hacia una Infancia Virtual? La imagen corporal sin cuerpo. Buenos Aires: Nueva Visión.

Marinas, José Miguel (2001). La Fábula del Bazar. Orígenes de la cultura de consumo. Madrid: Machado Libros.

Martínez-Collado, Anna (2007). Tecnoliberación. Ya somos Cyborgs. Disponible en http://rizomas.blogspot.com.es/ consultado el 18/3/2018 consultado el 18/3/2018.

Mcluhan, Marshall (2009). Comprender los medios de comunicación. Barcelona: Paidós.

Nadoroski, Mariano (2006). Dolor de escuela. Buenos Aires: Prometeo.

Negri, Antonio; Hardt, Michael (2002). Imperio. Barcelona: Paidós.

Palermo, Giulio (2008). El mito del mercado global. Crítica de las teorías neoliberales. Barcelona: El viejo topo.

Piscitelli, Alejandro (2009). Nativos digitales: dieta cognitiva, inteligencia colectiva y arquitecturas de la participación. Buenos Aires: Santillana.

Preciado, Beatriz (2008). Testo Yonki. Madrid: Espasa-Calpe.

Preciado, Beatriz (2010). Pornotopía. Arquitectura y sexualidad en «Playboy» durante la guerra fría. Barcelona: Anagrama.

Rodríguez Pascual, Iván (2000). "¿Sociología de la infancia?: aproximaciones a un campo de estudio difuso". Revista Internacional de Sociología, 26: 99-123.

Rodríguez Pascual, Iván (2007). Para una sociología de la infancia: aspectos teóricos y metodológicos. Madrid: CIS, Siglo XXI.

Stiglitz, Gustavo (Comp.) (2006). DDA, ADD, ADHD, como ustedes quieran. El mal real y la construcción social. Buenos Aires: Grama.

Wajcman, Gustavo (2011). El ojo absoluto. Buenos Aires: Manantial. 